\title{
AMMONIA FROM STEELWORKS
}

\author{
Valera-Medina A, Roldan A \\ College of Physical Sciences and Engineering, Cardiff University, Wales, UK
}

\section{ABSTRACT}

Ammonia has been produced over the last centuries in several ways, with the Haber-Bosch process leading current production due to its efficiency and feasible deployment. However, previous to the leading positioning of the Haber-Bosch process, ammonia used to be manufactured using coal-based gas works. Coke, a remnant of the process, has been widely used for steel production processes, thus making logic the integration of these gas facilities into the production of steel for better economic profiles. Although this ammonia production process is currently used only in a minor share of the total ammonia market, there are locations where it is still employed to obtain the chemical. This chapter is dedicated to the production of ammonia from such steelworks, detailing some of the history, fundamentals and current trends behind the process that set the foundations of ammonia as one of the main global chemicals.

\section{BACKGROUND}

Since the 1860s, ammonia obtained from the destructive distillation of coal was used as a source of nitrogen for fertilizer purposes. Ammonia liquor was obtained by sulphuric gas absorption that was employed after scrubbing coal gas with water. Ammonium sulphate, obtained from the process, was then used as fertilizer [4]. It is estimated that approximately 140,000 tons/year of this chemical were produced around Europe by the end of the nineteenth century.

It was in 1889 that Ludwig Mond, a German-British chemist, discovered, during his search of a process to manufacture ammonium sulphate, that coal combustion could produce ammonia when the reaction takes place with air and steam. The produced gas, in combination with other species, was named Mond Gas [5]. His findings suggested that low-quality coal could react with superheated steam producing high valuable gas. Dilute sulphuric acid sprays were then employed to remove the ammonia, forming ammonium sulphate in the process. Different from other processes, Mond's modification was based on the restriction of the supplied air, which was then filled with steam to generate low-temperature atmospheres. Since these low temperatures were lower than the temperatures required to dissociate ammonia, the recovery of the latter was maximized [5]. Mond realised at the time the great potential of ammonia to satisfy the fertilizer market, although his initial interest was to ensure the supply of ammonia to his alkali factory.

Mond's process was utilised at Brunner from 1902, which was followed by implementation at various other sites in Britain, Argentina, Spain and the US by 1903. These plants required massive capital investment to be economically viable. Over 182 tonnes of coal per week were employed to produce ammonia profitably with efficiencies as high as $80 \%$ [19]. It is estimated that the production of British ammonium sulphate reached $\sim 220,000$ tons/year by 1902 , with $68 \%$ obtained from gas works and $9 \%$ from coke, carbonizing and Mond gas works [4]. Two-thirds of the total production were exported across the globe and used as fertilizer. An important destination for British fertilizer was Japan until the beginning of World War I [4]. By then, the production of ammonium sulphate was estimated at around 270,000 tons/year [10]. 
Further technological advances took place across Europe driven by companies such as Semet and Evence Coppee that developed new techniques to increase the ammonia recovery from coke ovens. Amongst other leaders that worked on this subject, Heinrich Koppers introduced the coke oven process into the US industry in 1907. Establishing Heinric Koppers AG in 1904, he created the so-called "half direct" process for recovery tar and ammonia from coke oven gas. By 1923, 90\% of all coke oven plants in the Ruhr district used this process [11].

Before World War II, significant quantities of ammonia were manufactured from derived coke producing processes via coal conversion. Coal-based ammonia production dominated the industry until then [1]. It is estimated that around 2.7 million tons of ammonia per year were produced in this manner [2]. However, the situation would change by 1960, where most of the ammonia (by this time, 16 million tons per year) was obtained using natural gas from which hydrogen was obtained. Close to the end of the last century, coal and coke only accounted for $10.9 \%$ of the feedstock to produce ammonia. Some industries still produce ammonia from steelwork gases. Examples are the fertilizer plants located in India at Durgapur (West Bengal), Rourkela (Orissa) and Bhilai (Madhya Pradesh), and those at Burnpur and Kulti (West Bengal) [7].

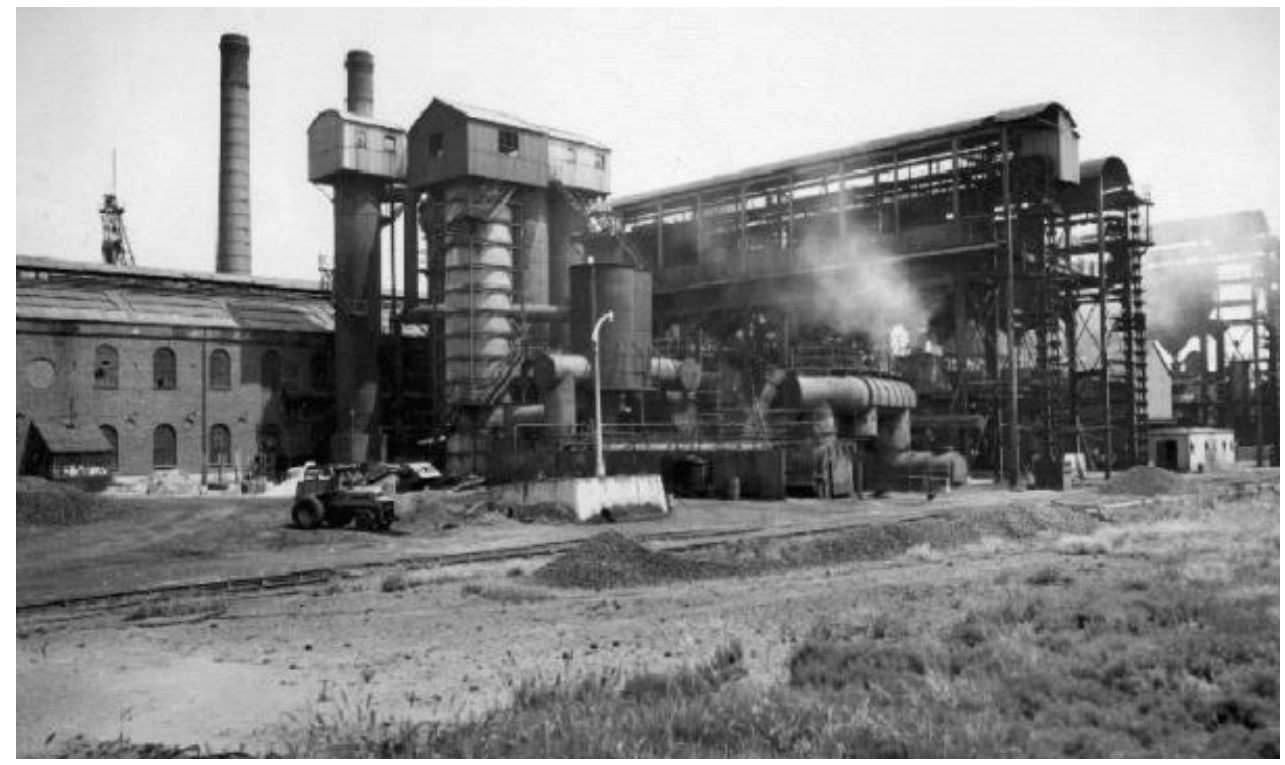

Figure 1. The Former South Staffordshire Mond Gas Company works [19]. Courtesy of the National Grid Archive, UK.

However, with the technological advancements and for the first time, ThyssenKrupp announced the production of ammonia using steel mill gases [3]. Findings obtained through the Carbon2Chem project in collaboration with Fraunhofer-Gesellschaft, the Max Planck Society and 15 other partners (with an estimated €60M budget) revealed that ThyssenKrupp succeeded in producing pure chemicals from these steel waste streams in 2018. The first ammonia production took place in the Carbon2Chem technical centre in Duisburg, a pilot plant in which laboratory results were validated under practical industrial conditions using gases from regular steel mill operation [3]. The steel mill gas is comprised of $44 \%$ nitrogen, $23 \%$ carbon monoxide, $21 \%$ carbon dioxide, $10 \%$ hydrogen and $2 \%$ methane, thus making it suitable for the production of carbon and hydrogen synthetic gases such as ammonia. The solution developed in Duisburg could be transferred to over 50 steel mills worldwide [3]. This scenario, combined with new energy storage trends, opens the possibility of using ammonia for further applications through reduced cost and increased efficiencies. 


\section{PRODUCTION}

Coke oven gas (COG) is a mixture of gases produced in steel plants during the carbonization of coal. It contains a great variety of gases, which vary depending on the process and coal source. However, concentrations tend to be around $50 \% \mathrm{H}_{2}, 25 \% \mathrm{CH}_{4}, 8 \% \mathrm{CO}, 6 \% \mathrm{~N}_{2}$ and minor amounts of hydrocarbons, $\mathrm{CO}_{2}$ and impurities (i.e. ammonia, hydrogen sulphide, hydrogen cyanide, ammonium chloride, benzene, toluene, xylene, naphthalene, tars and carbon disulphide) [1,9]. Coke oven gas is still employed to produce ammonia by steam reforming or by separation of hydrogen by cryogenic processes [9]. Before these processes, the precipitation of tar is required to avoid corrosion and unwanted emissions [6]. The cryogenic processes involve liquid nitrogen wash [1, 7], which is obtained from air separation units to produce oxygen for the steelworks [2]. Combining nitrogen and hydrogen, as in the following reaction, yields ammonia [8].

$$
\mathrm{N}_{2}+\mathrm{H}_{2} \leftrightarrow \mathrm{NH}_{3} \Delta_{\mathrm{r}} \mathrm{H}^{0}=-45.9 \mathrm{~kJ} / \mathrm{mol}
$$

The general principle observed in the sequence of operation in the by-product plant is to follow the tar/liquor separation from the gas by sequential removal of components [10]. The operation is usually carried out at positive pressures (70-150 mBar) to avoid air in-leaks. The normal sequence of operation is as follows [9],

1. Tar and liquor separation

2. Primary gas cooling

3. Compression in exhausters

4. Electrostatic tar droplet removal

5. Secondary/final gas cooling

6. Ammonia removal

7. Benzole removal

8. Naphthalene removal

9. Hydrogen sulphide removal.

Sequences may vary depending on the by-product plant and processes.

\section{AMMONIA REMOVAL PROCESSES.}

The retrieval of by-products from steelworks is significant as there is a potential benefit. Nevertheless, the COG needs to be treated and purified of contaminants that have the potential to foul and corrode pipework $[9,15,17]$. Yields from this treatment depend on several factors, mainly related to the carbonisation conditions [9].

Historically, COG by-product constituents were valuable, often more so than the coke itself, particularly within the agricultural sector. Currently, the emphasis on the by-product plant to purify COG became more about the treatment of the gas to produce environmentally clean fuel and less about the recovery of by-products. Indeed, there has been a significant focus on optimizing the industrial purification process of coke-oven gas in order to achieve a cost-efficient and environmentally friendly process. Germany, in particular, has developed coke plants that have the highest environmental standards in comparison to other coking facilities. Nevertheless, there is still further research being carried out to improve the efficiency and environmental standards of cokeplants across the globe [17]. Among the COG components, the recovery of ammonia is of particular interest due to economic and environmental reasons.

As mentioned above, COG is a complex gas with many constituents, some of which are useful for many applications; for example, hydrogen, methane and carbon monoxide are retained for the production 
of steel and production of extra power; paraffinic and unsaturated gases are also retained for further uses $[9,17]$. Small traces of harmless, inert gases such as oxygen, nitrogen or $\mathrm{CO}_{2}$ are also kept in the final gas [9]. Ammonia removal from both the COG and the flushing liquor is now a universal requirement of coke-ovens as it is corrosive to carbon steel pipework and oxidation forms nitrogen oxides, which are detrimental to the environment due to the over-nitrification of ground waters and soils besides the formation of $\mathrm{NO}_{x}$ noxious gases.

\section{Ammonia removal from flushing liquors}

Conventionally, excess flushing liquor was commonly used to quench the hot coke. However, this is no longer an acceptable practice for environmental reasons. Alternatively, the flushing liquor distillation followed by further treatment in a biological effluent treatment (BET) plant would remove its ammonia content. The distillation stage reduces operational costs and involves feeding the flushing liquor to a distillation column and feeding a countercurrent flow of stripping stream beneath it, which causes the ammonia to vaporise out of the overhead vapours before further treatment. The treated liquor is then cooled and passed onto the BET plant for further ammonia removal by decomposing, for instance, ammonium chloride and ammonium sulphate, upon alkali addition.

Traditionally, calcium hydroxide was used as the alkali source as it was inexpensive and readily available. However, the formation of insoluble calcium salts caused fouling problems. Alternatively, sodium carbonate was used as insoluble salts were not formed, although the impurities present caused similar problems of fouling. Currently, sodium hydroxide is used, and although it is more expensive than traditional alkaline salts, it outweighs previous fouling limitations.

\section{Ammonia removal from COG}

The current technology to remove ammonia from COG streams is well established, and although the so-called water-wash is the more conventionally method, others such as the ammonium sulphate and Phosam processes are also employed $[9,15]$.

The ammonium sulphate method involves the retention of $\mathrm{NH}_{3}$ in solution by the addition of sulphuric acid $\left(\mathrm{H}_{2} \mathrm{SO}_{4}\right)$ generating ammonium sulphate $\left(\left(\mathrm{NH}_{4}\right)_{2} \mathrm{SO}_{4}\right)[9]$.

$$
\mathrm{NH}_{3}+\mathrm{H}_{2} \mathrm{SO}_{4} \rightarrow\left(\mathrm{NH}_{4}\right) \mathrm{HSO}_{4}+\mathrm{NH}_{3} \rightarrow\left(\mathrm{NH}_{4}\right)_{2} \mathrm{SO}_{4}
$$

The $\mathrm{NH}_{4}\left(\mathrm{HSO}_{4}\right)$ is recovered by crystallization before the formed crystals are centrifuged, washed, and then dried. This method of $\mathrm{NH}_{3}$ recovery differs in practice depending on the type of gas/liquor contacting device and the equipment used for crystallization. There is, however, an economic disadvantage with the ammonium sulphate process; the price of $\mathrm{H}_{2} \mathrm{SO}_{4}$ required to form $\left(\mathrm{NH}_{4}\right)_{2} \mathrm{SO}_{4}$ can cost twice as much as the value of the produced ammonium sulphate crystals.

An estimated 2.5-3.0 kg of ammonia are produced per ton of coal employed for the production of coke due to the high temperatures of the process. As previously stated, ammonia or ammonium sulphate scrubbed from COG gas are still employed as fertilizer in various places across the world. There are three methods used for this recovery: direct, indirect and semi-direct [1-2]. These are described in Table 1. 
Table 1. Ammonium sulphate scrubbing methods $[1-2,20]$

\section{Method Description}

\begin{tabular}{l|l}
\hline Direct & $\begin{array}{l}\text { Tar is removed by cooling down the } \\
\text { inlet gas. The gas is then passed } \\
\text { through a saturator and washed } \\
\text { with } \mathrm{H}_{2} \mathrm{SO}_{4} \text {. Ammonium sulphate is } \\
\text { produced, centrifuged, washed } \\
\text { and dried. }\end{array}$
\end{tabular}

Indirect The gas is cooled and liquefied. Liquors are passed through a bubble-cap still. "Free" ammonia from the salts is released when the liquors get in contact with steam, while posterior treatment through lime decomposes the "fixed" ammonium salts. Ammonia can then be stripped with water or combined with sulphuric acid to form ammonium sulphate.

\begin{tabular}{l|l}
\hline Semi- & This method offers a solution that \\
Direct & $\begin{array}{l}\text { incorporates concepts from both } \\
\text { the indirect and direct processes. } \\
\text { The gas is cooled, and traces of tar } \\
\text { are removed. Aqueous } \\
\text { condensates are sent to ammonia } \\
\text { spill. The mainstream and the } \\
\text { released ammonia are combined } \\
\text { and heated up to } 70^{\circ} \mathrm{C} \text {. The gas is } \\
\text { scrubbed with a nearly saturated } \\
\text { ammonium sulphate solution } \\
\text { comprised of } 5-6 \% \mathrm{H}_{2} \mathrm{SO}_{4} \text {. This last } \\
\text { part of the process takes place at } \\
\text { temperatures between } 50 \text { and } \\
70^{\circ} \mathrm{C} .\end{array}$
\end{tabular}

Advantages

High recovery of effluents with low investment and reduced operating expenses.

The method is the preferred option for extensive facilities, with more significant ammonia recovery and salts free from impurities.

The method has considerable flexibility, with a product ammonium sulphate) free of impurities.

\section{Disadvantages}

Products could be
contaminated (i.e. tar, pyridines and chloride). If the reactor is used as scrubber and crystallizer, the $\mathrm{pH}$ is difficult to handle to reduce impurities. Chloride from fuel or water could also react with the mixture and generate problems. corrosion

The effluent disposal is highly problematic, with high ammonia losses because of reduced reaction and absorption. Due to the higher complexity, the operation is more expensive than with the direct method.

Although superior to the direct and indirect methods, the water balance during the saturation operation needs to be carefully controlled to enable the proper reaction of species. Moreover, salt incrustation could lead to maintenance problems.

The Phosam method for ammonia recovery was developed by United States Steel to produce pure anhydrous $\mathrm{NH}_{3}$. The high-value product means that this process is much more economically favourable than the ammonium sulphate process. The Phosam process selectively absorbs $\mathrm{NH}_{3}$ from COG via direct contact with an aqueous solution of phosphate, which is added only in minimal quantities. This process has very high efficiency achieving $>99 \%$ recovery of $\mathrm{NH}_{3}$ from the COG [16]

$$
\mathrm{NH}_{3}+\mathrm{H}_{3} \mathrm{PO}_{4} \rightarrow\left(\mathrm{NH}_{4}\right) \mathrm{H}_{2} \mathrm{PO}_{4}+\mathrm{NH}_{3} \rightarrow\left(\mathrm{NH}_{4}\right)_{2} \mathrm{HPO}_{4}+\mathrm{NH}_{3} \rightarrow\left(\mathrm{NH}_{4}\right)_{3} \mathrm{PO}_{4}
$$


Anhydrous ammonia can be used as a fertilizer by injecting it directly into the ground - common in North America -, and as an industrial refrigerant. Under license control, it is also used in the production of methamphetamines.

The water-wash method involves the use of water to strip contaminants from COG [15]. Aqueous absorption liquor is fed into an $\mathrm{NH}_{3}$ washer vessel in a counter-current flow to the COG leading to ammonia solution of high concentration. The following step of distillation and recirculation of the condensed phase, which is further biologically treated to eliminate any residual $\mathrm{NH}_{3}$.

The washer vessel is usually placed after the tar precipitator in the by-product plant. The COG requires cooling before it enters the washer. Since this part of the process is temperature dependent, it has been found that $\mathrm{NH}_{3}$ removal is most efficient at low temperatures. Indeed, the solution of gases such as $\mathrm{NH}_{3}$ depends on the liquid phase temperature according to Henry's law of solubility. However, in the steelwork industry, the washer must not be operated at lower temperatures than the outlet temperature of the gas cooling stage to avoid fouling by naphthalene precipitation.

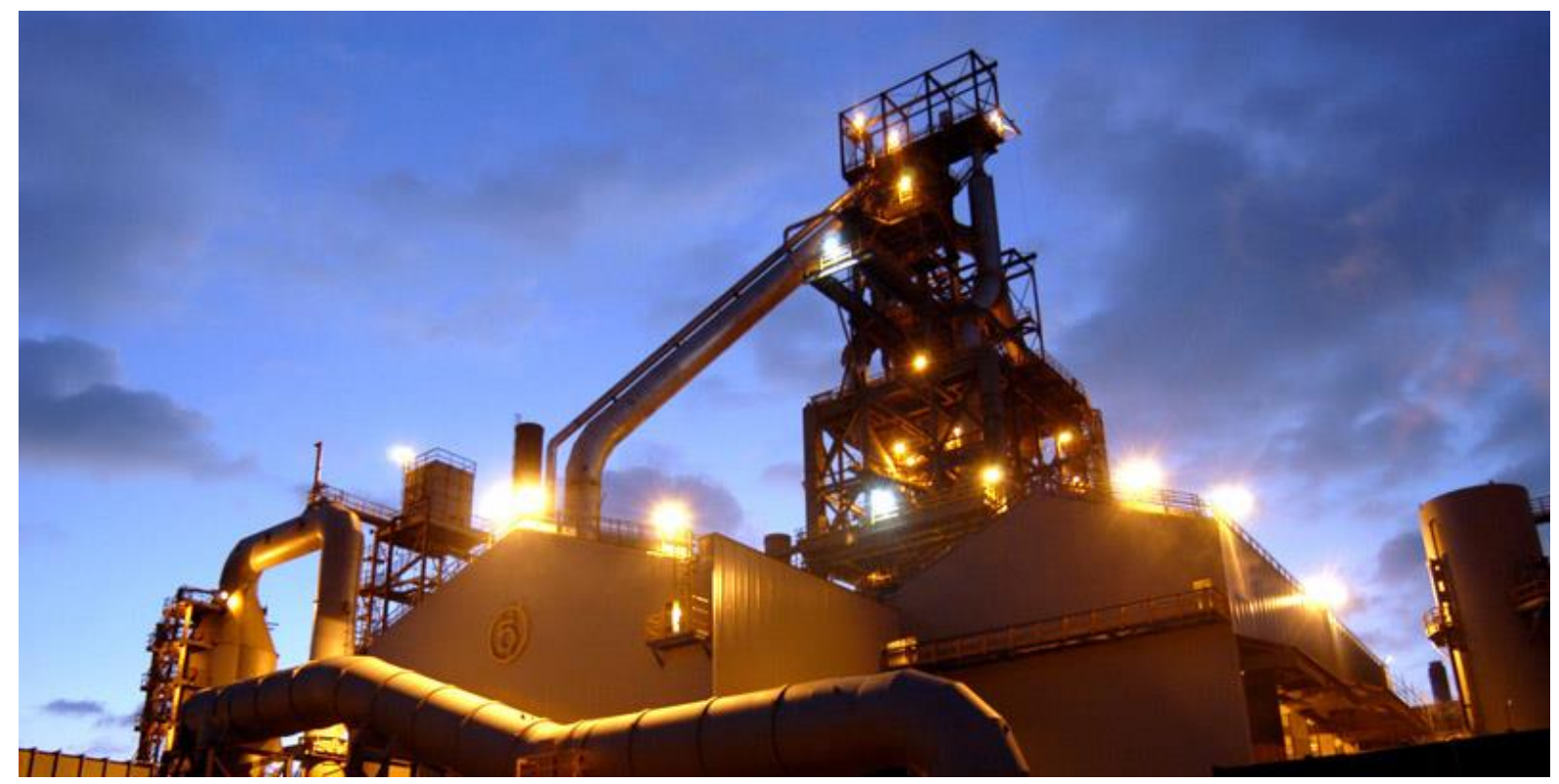

Figure 2. Tata Steel Port Talbot, UK. Although not commercialized anymore, ammonia traces from COG processing can potentially be used in other processes. Courtesy of Tata Steel, UK.

Alternative new technologies such as membranes are easing even further the removal of ammonia from flushing liquors [21]. Membrane distillation is being investigated worldwide as a high efficient and affordable technology [21-22]. Hydrophobic membranes (flat-sheet, hollow fibre, and spiral wound) are preferred for ammonia extraction due to their hydrophobic characteristics, excellent organic resistance, and chemical stability with acidic and alkaline solutions [21]. The strong hydrophobicity of the membrane prevents liquid transportation through it, thus facilitating the separation of species with different vapour pressures [23]. The partial pressure gradients across the membrane results in the transfer of the volatiles from the liquid phase to the vapour phase. As the temperature gradient is maintained across the membrane, the transport of water vapour occurs continuously. Meawhile, other species remain on the other side of the membrane, thus separating water from the mixture. Conventional flat-sheet porous have been applied for membrane distillation with efficiencies varying between $70-90 \%$ [24]. 


\section{UTILIZATION OF AMMONIA FROM STEELWORKS}

Ammonia from steelworks can be used in many ways. Similar to ammonia produced by any other method, the versatility of the chemical enables its use for fertilizing, heat production and chemical process applications. However, differently from other processes, ammonia from steelworks can be employed using gaseous waste streams only available on site to reduce cost or to generate extra heat/power for processes needed to produce steel. Therefore, this section is dedicated to evaluating some of these specific processes.

\section{Ammonium sulphate}

Ammonium sulphate can be used as a fertilizer. Although its use is relatively smaller when compared to urea, ammonium nitrate solutions and anhydrous ammonia for this application [1], ammonium sulfate can still be employed for this application if available. The manufacturing and delivery method will vary depending on the customer's specifications.

\section{Incineration}

Incineration of ammonia vapours product of the coke oven gas process has been a common practice since the 1960s [10]. Ammonia, with a low heating value (LHV) of $18 \mathrm{MJ} / \mathrm{kg}$, can be burned using a pilot flame without the need of other doping agents [12]. Companies around the globe employ these systems to reduce costs and mitigate contaminants, many of which are intrinsically dedicated to the production of steel [13]. However, the process carries out the production of emissions such as NOx and SOx, which are extremely detrimental to the atmosphere. Since ammonia contains nitrogen, its combustion at elevated temperatures generates NOx emissions higher than those established for environmental regulatory purposes, requiring the implementation of novel combustion techniques to reduce temperatures whilst burning chemicals such as sulphur content species.

Therefore, the presence of these unwanted emissions in the stack has led to a close review of the process, with new installations now being used only for standby or emergency applications as shortterm measures, i.e. for maintenance or unstable operation [10]. Moreover, some companies have looked at incineration as a possible solution to some of their heating requirements. Specialised steel production, which employs ammonia as part of their process, have attempted to utilise ammoniacontaining gases for additional heating applications [14].

\section{Concentrated Ammonia Liquor}

Ammonia liquor can be produced from various ammonia vapour streams. A preliminary condensation is carried out to minimise water content. The condensate is returned to the distillation column, with the remaining vapours then condensed to produce ammonia liquor [10]. Ammonia liquor produced by this method has a limited concentration of $15-20 \%$ ammonia, a consequence of the ammonium carbonate that is also formed on the condenser surface. This problem can be reduced by reducing acid gases such as carbon dioxide by "deacidification" processes via steam stripping [10].

A standard method to cool and condense ammonia vapours is by direct contact with recirculated cooled ammonia, thus avoiding localised sub-cooling that can lead to crystallisation and fouling. The production of concentrated ammonia liquor is also used to provide a low-cost standby in plants where the regular ammonia handling facilities are out of service for maintenance [10].

Another option is to use the concentrated ammonia liquor or anhydrous ammonia, i.e. obtained from the former, for power purposes. Hewlett et al. [15] examined the potential of using ammonia in both its ammonia vapour (AV) and recovered anhydrous ammonia (AA) forms, to produce power using gas 
turbine (GT) technology. The priority of the study was to minimize $\mathrm{NO}_{\mathrm{x}}$ concentrations and other harmful emissions while optimizing operational performance. After analyses using 0-D, 1-D and ASPEN software with various combinations of ammonia and COG blends, the group concluded that ammonia from steelworks could be used to produce power at efficiencies up to $46 \%$. Further information can be found in [15]. Figure 3 shows a representative flame obtained with such blends. According to numerical analyses, adding $15 \%$ COG to both the AV and AA gives the optimal balance of reactivity and lower pollutant products. Therefore, the potential of using ammonia product from coke processes might have a viable application to support energy storage in steelwork complexes.

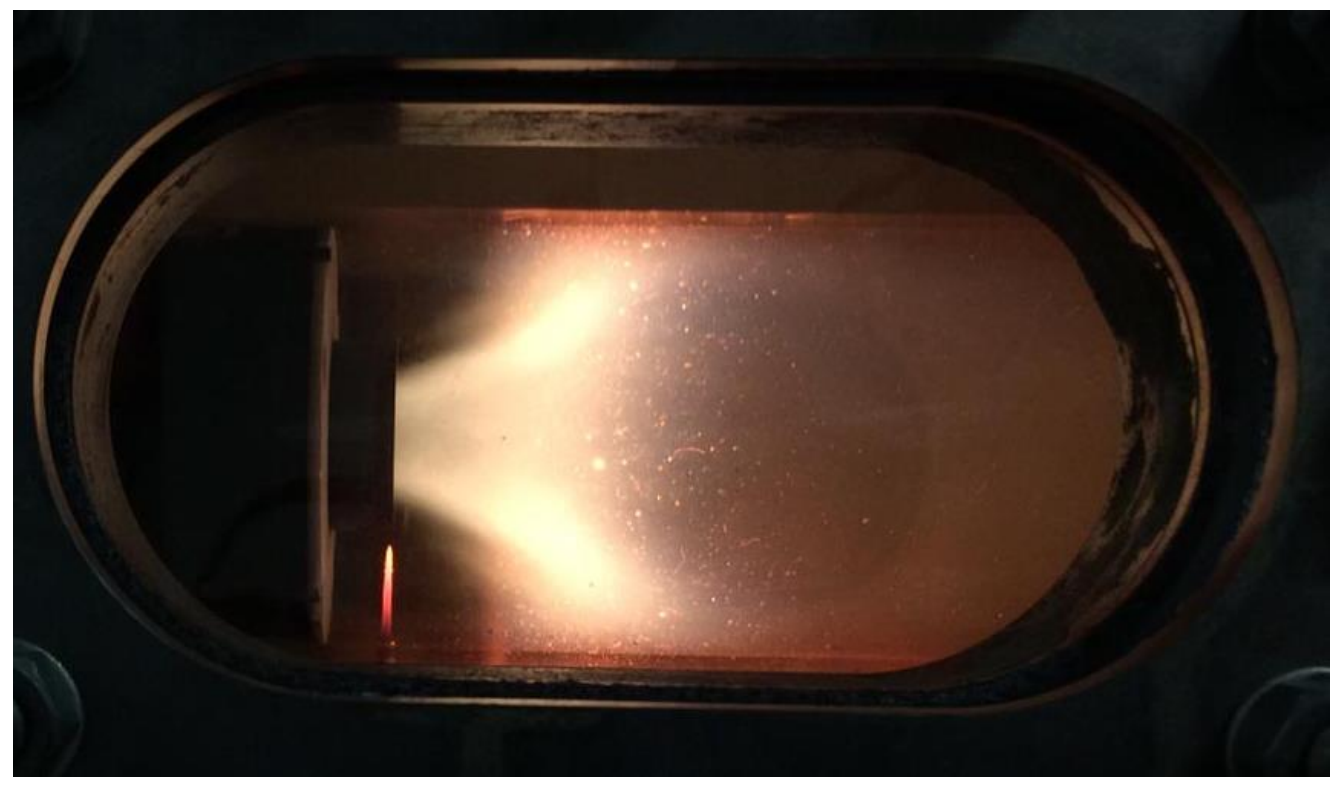

Figure 3. Ammonia-COG flame.

\section{Catalytic Destruction}

Another option presented by the industry was to destroy ammonia by cracking the molecule. Instead of producing contaminants ( $\mathrm{NOx}, \mathrm{SOx}$ ) or adding extra costs to the production of ammonium sulphate, the concept seeks to recover hydrogen from the ammonia molecule, therefore enabling the use of hydrogen in other parts of the processor as a doping agent to increase combustion performance.

The process employs COG that, in conjunction with vapours, air and ammonia are fed to a burner with high flowrate controls. The reaction favours the combustion of COG, thus creating an atmosphere consisting of ammonia vapours and COG combustion products at $\sim 1150^{\circ} \mathrm{C}$. A catalytic nickel-based bed is used, which cracks the ammonia into hydrogen and nitrogen. Hydrogen cyanide reacts with the water vapour producing nitrogen, hydrogen and $\mathrm{CO}_{2}$. The gases then pass through a waste heat boiler to be cooled to $300^{\circ} \mathrm{C}$. The gases may pass directly to the raw COG main, thus closing the loop, or they may be further cooled by water for other purposes [10]. This process enables a reduction of NOx or SOx emissions.

\section{Final Remarks}

Ammonia from steelworks used to be the primary source for the production of fertilizers before the end of the first half of the twentieth century. However, due to the increasing introduction of natural gas and its cleaner processing, ammonia from steelworks was relegated, now sharing less than $12 \%$ of the overall production of $\mathrm{NH}_{3}$ worldwide. Although some developing economies still use this concept, costing and environmental regulations have led to a decline of ammonia production via this method. However, since steel is a significant component of today's society, the use of ammonia from the 
generation of coke oven gas or steel mills can still be a potential source for chemical storage that could be implemented for backup applications in power and heat supply auxiliary processes. Current studies and large-scale projects show that ammonia, recovered from waste streams found in the entire steel production chain, can have significant advantages for energy support and chemical production. Thus, further progress on the topic should be expected in the years to come.

\section{ACKNOWLEDGEMENTS}

Cardiff University gratefully acknowledges the support from the Welsh European Funding Office (WEFO) through its program "Flexible Integrated Energy Systems (FLEXIS)", project no. 80835.

\section{REFERENCES}

[1] Vasant G, Krishnamurthy VN, Gowariker S, Dhanorkar M, Paranjape K. 2009. The Fertilizer Encyclopedia, ed. Wiley. 860pp.

[2] United Nations Industrial Development Organization (UNIDO), 1998. Fertilizer Manual, Kluwer Academic Publishers, $2^{\text {nd }}$ Edition. 619pp.

[3] BioAge Group. "ThyssenKrupp produces ammonia from steel mill gases; Carbon2Chem" Available in Green Car Congress [Online] www.greencarcongress.com [Accessed $14^{\text {th }}$ February 2019]

[4] Travis AS. 2018. Nitrogen Capture. The growth of an international industry (1900-1940). Springer, 410pp.

[5] R.D. Wood and Co. Philadelphia, 1903. "Mond Gas". [Online]

https://archive.org/stream/mondgas00woodrich\#page/n5/mode/2up [Accessed 14th February 2019]

[6] Caillat S. Burners in the steel industry: utilization of by-product combustion gases in reheating furnaces and annealing lines, Energy Procedia 2017;120:20-27.

[7] Kolay AK. Manures and Fertilizers. Weinheim, Germany: Atlantic Publishers and Distributors; 2007, pp. 55.

[8] Uribe-Soto W, Portha J-F, Commenge J-M, Falk L. A review of thermochemical processes and technologies to use steelworks off-gases, Renewable and Sustainable Energy Reviews 2017;74:809823.

[9] Wright K. Coke Oven Gas treatment. Tar, Liquor, Ammonia. In The Coke Oven Manager's Year Book, pp. 221-257.

[10] Vroomen H, 2013. "The History of Ammonia to 2012" [Online]. By The Fertilizer Institute, Available in www.firt.org/sites/default/files/2Vroomen.pdf [Accessed $20^{\text {th }}$ March 2019].

[11] Dierschke A, 1955. "Development of the Coke Oven Industry" [Online]. By the JSTAGE, Available in https://www.jstage.jst.go.jp/article/jie1922/35/3/35 3 157/ pdf [Accessed 20 ${ }^{\text {th }}$ March 2019].

[12] Valera-Medina A, Xiao H, Owen-Jones M, David WIF, Bowen PJ. Ammonia for Power, Progress in Energy and Combustion Science 2018;69:63-102.

[13] Masons P. The Port Talbot Steelworks (Power Generation Enhancement) Order. TATA Steel, Report MAH1.01, pp. 211. 
[14] Fatla OHM, Valera-Medina A, Robinson F, Cichuta M, Beynon N. Development of convection in high temperature coil annealing furnaces using rotating cylinder technique, Applied Thermal Engineering 2018;129:1392-1402.

[15] Hewlett SG, Valera-Medina A, Pugh DG, Bowen PJ. Gas turbine co-firing of steelworks ammonia with Coke Oven Gas or Methane: A fundamental and cycle analysis, Proceedings of the ASME Turbo Expo 2019, Phoenix, USA. Ref. No. GT2019-91404.

[16] Ratnayaka DD, Brandt MJ, Johnson KM. Water Supply, $6^{\text {th }}$ Edition, Butterworth-Heinemann, 2009, 744pp.

[17] Razzaq R, Li C, Zhang S. Catalytic methanation of $\mathrm{CO}$ and $\mathrm{CO} 2$ in coke oven gas over Ni-Co/ZrO2CeO2, Fuel 2013;113:287-299.

[18] Paul Wurth, "Cove Oven Gas Treatment" in SMS Group, Available Online, http://www.paulwurth.com/Our-Activities/Cokemaking/Coke-Oven-Gas-Treatment [Accessed $10^{\text {th }}$ May 2019]

[19] CLAIRE, 2014 "Gasworks Profile D: Produced Gas Plants" supported by National Gas Grid and Parsons Brinckerhoff, Available Online, https://www.claire.co.uk/component/phocadownload/category/9-other-cl-airedocuments?download=433: gasworks-profile-d-producer-gas-plants [Accessed $9^{\text {th }}$ May 2019]

[20] Sweeney MP, 1953. "Coke oven by-product recovery process" Patent US2943911A. Available Online, https://patents.google.com/patent/US2943911 [Accessed 23rd May 2019].

[21] Kunz A, Mukhtatar S. Hydrophobic Membrane Technology for Ammonia Extraction from Wastewaters, Eng. Agrícola 2016;36:377-386.

[22] Zhao ZP, Xu L, Shang X, Chen K. Water regeneration from human urine by vacuum membrane distillation and analysis of membrane fouling characteristics, Sep. Purif. Technol. 2013: 118: 369376.

[23] Udert KM, Wächter M. Complete nutrient recovery from source-separated urine by nitrification and distillation, Water Res. 2012;46:453-464.

[24] El Bourawi MS, et al. Application of vacuum membrane distillation for ammonia removal, J. Memb. Sci. 2007;301:200-209. 